\section{A AMAZÔNIA EM MÚLTIPLAS FACES}

FERRETTI, Sérgio; RAMALHO, José Ricardo (Org.).Amazônia. Desenvolvimento, meio ambiente e diversidade cultural. São Luís: EDUFMA, 2009. 224 p.

\section{Eliana Tavares dos Reis}

A obra Amazônia. Desenvolvimento, meio ambiente e diversidade cultural é constituída de um conjunto de dez capítulos produzidos por pesquisadores de diferentes áreas de conhecimento das Ciências Sociais, vinculados à Universidade Federal do Maranhão e à Universidade Federal do Rio de Janeiro. A interlocução entre eles se deu nos marcos do convênio PROCAD/CAPES, e seus estudos foram reunidos e organizados pelo antropólogo Sérgio Figueiredo Ferreti e pelo sociólogo José Ricardo Ramalho, professores, respectivamente, das instituições de ensino mencionadas.

Para além do valor temático, tem-se, nessa coletânea, uma riqueza de focos de investigação e de abordagens teóricas e metodológicas que retratam a multiplicidade de possibilidades interpretativas de processos, atores e lógicas sociais, políticas, econômicas e culturais. Os trabalhos contribuem decisivamente para o desvendamento do modo como dinâmicas específicas (basicamente nos estados do Pará e do Maranhão) são definidas e definem ações e relações que conformam cadeias de interdependências muito mais amplas. Conjuga-se a isso a oportunidade de atentar-se para a série de discursos, negociações, agentes e concorrências que compõem tais cadeias e que são responsáveis pela edificação da Amazônia como referência de síntese para problemáticas políticas e para posicionamentos socialmente relevantes que colaboram para a sua existência objetiva.

Formas de legitimação de políticas públicas, estratégias empresariais, resistências identitárias, configurações de perfis e manifestações culturais são algumas das dimensões tratadas e que podem ser localizadas num continuum entre ideias de desenvolvimento e de preservação. Projetadas do local ao global, do passado ao futuro e mediadas por noções de impacto, riscos e efeitos, esses enfoques se traduzem nas controvérsias em torno de definições de meio ambiente, desenvolvimento sustentável, diversidade cultural e até mesmo de esquemas analíticos mais ou menos eficientes para a compreensão dos fenômenos sociais.

Observando-se a atualização de relações dicotômicas clássicas (lidas do ponto de vista científico e normativo) como as de tradição versus modernidade e a de mudança versus continuidade, propõe-se aqui atribuir essa regularidade para pontuar as singularidades dos diferentes capítulos do livro em pauta. Ou seja, indaga-se como essas dicotomias emergem nas discussões de cada autor, no intuito de explicitar não somente a importância de propostas desse tipo como parte integrante da consagração de problemas sociais, como também de formulação de questões relevantes para as ciências sociais.

O processo de instauração do Programa Grande Carajás (PGC) na Amazônia Oriental, com vistas à exploração de ferro gusa e carvão vegetal, é um dos cenários em que se situam os primeiros estudos presentes na obra. No quadro de referência, são sublinhados aspectos tais como as "apostas" do governo federal no PGC e a atuação da, então estatal, Companhia Vale do Rio Doce, responsável pela construção da Estrada de Ferro Carajás (EFC), que une a serra dos Carajás (Pará) ao porto do Itaqui, em São Luís (MA). A intervenção nessa área teria como fim a industrialização e a modernização do país e como justificativa a potencialidade em termos de recursos naturais de um espaço considerado como um "vazio demográfico" e, portanto, também adequado à expansão territorial.

Rodrigo Salles Pereira dos Santos discute as modificações nos "modelos e papéis institucionais" do Estado Nacional brasileiro, para afirmar justa- 
mente a persistência de uma "estratégia desenvolvimentista" nas "ações e representações da modernização induzida nos últimos 40 anos”. O autor observa que o Estado demiurgo, que outrora se apresentava como o artífice direto das intervenções econômicas ("modelo centralista-autoritário" dos anos sessenta), passaria a desempenhar dois papéis complementares (com o "modelo descentralizado-democrático”): a gestão e sustentação de “infraestruturas públicas, de subsídios à atividade econômica e da incorporação de parte dos custos privados”; e a promoção das condições necessárias para a existência de "novos grupos econômicos, priorizando, sobretudo, a internacionalização, a orientação exportadora voltada à formação de superávits comerciais e à competitividade no setor mínerometalúrgico” (p. 85).

Pode-se pensar em como as transações econômicas globalizadas e as regulações pelo mercado, que visam ao comércio em escala internacional, facilitam o surgimento de empresas multinacionais com diferentes estratégias de mercado. Do mesmo modo, pode-se perguntar sobre os efeitos das iniciativas econômicas priorizadas e dos mecanismos de legitimação utilizados por agentes estatais e empresariais, tal como a criação de condições propícias de contestação em níveis igualmente globais.

Nessa linha, Marcelo Sampaio Carneiro, ao analisar dois mecanismos de certificação da atuação das empresas na Amazônia Oriental, revela processos mais abrangentes de ajuste aos parâmetros de conduta econômica e social exigidos internacionalmente. Esses diferentes "dispositivos de julgamento [são] destinados a construir a legitimidade das empresas submetidas à contestação da crítica social” (p. 20), e, portanto, ocupam um lugar central na apreciação e no controle dos "impactos sociais e ambientais derivados da implantação da atividade carvoeira e siderúrgica" (p. 34). Composta por porta-vozes localizados nos mais diferentes domínios sociais (midiáticos, organizações não-governamentais, instâncias governamentais, etc.) e geográficos (regionais, nacionais e internacionais) e com as mais variadas causas (ambientais, econômicas, políticas e sociais), a de- finição dessa categoria é tributária das condições conjunturais e das "possibilidades de mobilização argumentativa” (p. 34). Tal perspectiva converge com a vinculação da certificação com "práticas modernas de exploração florestal e de relação capital-trabalho" (p. 21) e de "dignificação, formalização e modernização do trabalho na cadeia produtiva do setor siderúrgico" (p. 31), logo, como possibilidade de transposição de uma ordem anterior ou "tradicional".

É nesse mesmo complexo que as comunidades são impactadas por projetos como o PGC e por modalidades de atuação utilizadas pelas empresas segundo os diversificados interesses em jogo. Horácio Antunes de Sant'Ana Júnior e Maria José da Silva Aquino lembram que as transformações das representações sobre o "meio ambiente", a "causa ecológica” e sua institucionalização - processada desde o final da década de 1960 - ajudaram na percepção da Amazônia "como reserva de biodiversidade e laboratório de políticas ambientais", o que incidiu na "criação de órgãos ambientais e na implementação de políticas de proteção e conservação do meio ambiente pelo governo brasileiro" (p. 65). Esse é o caso das Unidades de Conservação (UCs) fixadas no Sudeste do Pará (Província Mineral Carajás), que refletem a convergência dos interesses da mineradora Vale e do Instituo Chico Mendes de Conservação da Biodiversidade - integrante do Instituto Brasileiro do Meio Ambiente (IBAMA) - na preservação da floresta de "canga" (condição para a exploração de ferro). O mesmo não teria ocorrido com a formalização da reserva extrativista (RESEX) do Taim, em São Luís (MA), na qual a empresa, sem proveitos relacionados aos mangues, obstaculiza o "controle do uso de um território" almejado pelos órgãos ambientais e pelas "populações tradicionais" (p. 67).

Da mesma maneira, as comunidades indígenas seriam afetadas pelas investidas de atores governamentais, não-governamentais, empresariais, missionários, entre outros. Nesse sentido, o estudo de Elizabeth Coelho, Gustavo Politis, Almudena Hernando e Alfredo Ruibal, sobre as transformações 
do modo de vida dos Awá-Guajá (autodenominação e classificação externa, respectivamente), é particularmente primoroso, pois mostra como as múltiplas dimensões da organização social e as formas de existência e de percepção dos nativos são abaladas. Destaca-se o papel da Fundação Nacional do Índio (FUNAI), numa espécie de "colonização" dos Awá, em consonância com a imposição do PGC. Outrora nômades, circulando por extensões de matas pertencentes aos estados do Pará e Maranhão, o "novo modus vivendi" é marcado pelo sedentarismo, pela prática da agricultura e pela educação escolar. Os riscos e dificuldades de circulação (muito por conta da EFC) conduzem a readaptações nas suas formas de relacionamento com as moradias, os matrimônios, a caça, etc. Novos recursos exógenos passam a ser valorizados, tais como o domínio do português, redes e roupas industrializadas e uso de materiais sintéticos para adornos.

Benedito Souza Filho também questiona o abalo de empreendimentos externos nas identificações étnicas e territorialmente definidas, porém realça o sentido de resistência e de reinvenção das lutas de uma "população". Seu capítulo é dedicado ao exame do confronto entre "remanescentes de quilombo de Alcântara, no Maranhão, e setores do Estado em decorrência da implantação de uma base espacial" (p. 119-120) na década de 1980. Uma das principais opções analíticas do autor é "estabelecer um paralelismo" entre conflitos anteriores e o conflito atual, tomando como eixo as noções de quilombo, quilombola e de guerra. Indicando as mudanças nas ações do Estado contra os quilombolas, Souza Filho reforça a continuidade de uma luta cuja legitimidade é redefinida. Auxilia na reconfiguração dos seus parâmetros e sentidos a entrada em cena de porta-vozes e especialistas (antropólogos, arqueólogos, operadores do direito e historiadores) engajados na objetivação dessas "populações", garantindo sua "visibilidade cultural" e seus direitos face à ação "expropriadora" do Estado. Para ele, o "reconhecimento de grupos em diferentes partes do país como remanescentes de quilombos confirmou a importância e o papel dos intelectuais nesse processo" (p. 132).

As discussões em torno das invariabilidades e das modificações sofridas por "povos", "identidades", "manifestações culturais" e "rituais" resultantes das mudanças nas condições históricas, sociais, políticas e econômicas mais gerais são notadamente tratadas nos trabalhos antropológicos. Com essa perspectiva, encontra-se, na coletânea, um dos estudos produzidos por Sérgio Figueiredo Ferretti sobre as "festas religiosas populares". O autor retoma análises clássicas e contemporâneas das ciências sociais sobre festas e religião para fundamentar a investigação das "festas nos terreiros deculto afro-maranhenses", singularizadas pela combinação de dimensões do sagrado e do profano, conjugadas na oposição e complementaridade entre a "brincadeira" e a "obrigação" que as definem. Centrando-se mais detidamente no universo do "tambor de mina", ao qual tem dedicado muitos anos de pesquisa, Ferretti sublinha que ele pode ser entendido "como um dos elementos importantes de preservação de festas e tradições folclóricas ou da cultura popular" (p. 194).

As condições para o desenvolvimento de pesquisas que retratam a persistência, transmissão e valorização de manifestações dessa espécie, no âmbito das ciências sociais, foram criadas por transformações significativas nos estudo de "folclore" e de "cultura popular". Quer dizer, como demonstrou Maria Laura Viveiros de Castro Cavalcanti, elas se inserem numa dinâmica que beneficia o estabelecimento da pertinência dessas temáticas para o conhecimento antropológico e sociológico, assim como o reconhecimento de seus porta-vozes: os intelectuais e os pesquisadores. No Maranhão, a atuação e as pesquisas de Sérgio Ferreti ocupam uma posição de destaque na consolidação de estudos desse tipo. A autora analisa as inserções de intelectuais e pesquisadores em instâncias governamentais, os vínculos regionais e nacionais que estabeleceram entre si, a produção de políticas públicas de cultura e a relação desses fatores com a institucionalização das ciências sociais no estado. Para tanto, lança mão da apresentação de trajetórias exemplares de agentes responsáveis pela afirmação de espaços, de concep- 
ções, de temáticas e de prioridades políticas que alicerçaram o lugar conquistado pelos estudos de folclore e sua legitimidade acadêmica e científica.

Tal recurso analítico é igualmente adotado por Igor Gastal Grill, que visa a investigar os processos de diversificação e especialização das elites políticas do Maranhão e do Rio Grande do Sul. O autor analisa especialmente os investimentos profissionais e as "estratégias de reconversão de bases sociais em bases políticas, bem como [os] mecanismos e [os] princípios acionados com vistas à legitimação de formas de fazer e de conceber a política” (p. 137), ativados por deputados federais provenientes de famílias de imigrantes, notadamente italianas, alemães, sírias e libanesas. O cotejamento das duas configurações regionais permitiu delinear os confrontos entre estabelecidos e outsiders da política nos dois estados. É mediante a consideração das "tensões, disputas, interdependências, osmoses e interpenetrações", pesquisadas numa "perspectiva diacrônica, processual e comparativa" (p. 138), que o autor encontrou o terreno de produção e afirmação de posições, arenas e papéis políticos desempenhados por agentes com perfis e trunfos originais na disputa por cargos eletivos. Quer dizer, evidenciou a redefinição dos critérios de entrada e dos princípios de hierarquização do exercício da atividade política “via estratégias de reconversão" (p.158).

Pesquisas sobre configurações de relações políticas foram consagradas no âmbito das ciências sociais brasileiras, como é caso daquelas desen- volvidas por Maria Isaura Pereira de Queiroz e Maria Sylvia de Carvalho Franco. Elevando as contribuições dessas autoras para o pensamento político e social brasileiro, André Botelho empenhou-se na sistematização de elementos que as aproximam e daqueles que as distanciam no que tange às opções analíticas assumidas. Merece relevo, na ótica do autor, a problematização teórica e empírica do tratamento diferenciado e próprio que ambas oferecem à articulação entre "ação" e "estrutura" para a discussão e caracterização da "dominação política" gerada na "formação rural da sociedade brasileira”. Desse modo, nos termos colocados por Botelho, "elas conseguem divisar tanto aspectos persistentes na organização e reprodução social como a própria capacidade manifesta por indivíduos e grupos sociais de agirem e, desse modo, responderem criativamente ao contexto de estruturas em que se inserem” (p. 178).

Dentre os aspectos grifados por Botelho, dois podem ser desafiadores para a reflexão sobre o conjunto dos trabalhos presentes no livro ora resenhado. Em primeiro lugar, a relevância de se ponderar sobre a existência de relações de conflito e de violência no seio dos grupos sociais geralmente apresentados como unidades relativamente harmônicas, com objetivos e perspectivas relativamente comuns em relação aos "inimigos" apresentados com igual homogeneidade. E, em segundo lugar, a necessidade de se enfrentarem, com uma visão processual, as relações sempre conflituosas e contraditórias entre tradicional e moderno, continuidade e mudança, desenvolvimento e preservação.

(Recebido para publicação em maio de 2009) (Aceito em julho de 2009)

Eliana Tavares dos Reis - Professora Adjunta da Universidade Federal do Maranhão. Doutora em Ciência Política pela Universidade Federal do Rio Grande do Sul, com estágios de doutoramento em Paris (École des Hautes Études en Sciences Sociales e Paris I - Panthéon de la Sorbonne). Autora de artigos em revistas como Revista Pós-Ciências Sociais (UFMA), Ciências Humanas em Revista (UFMA), Cadernos Ceru (USP), Tomo (UFS), História Social (Unicamp), Revista de História (UFES), Sociologias (UFRGS) e Cadernos de Ciência Política (UFRGS). Co-organizou a coletânea "Estudos de Grupos Dirigentes no RS: algumas contribuições recentes (2008). eliana1reis@terra.com.br 